\title{
Determination of Cost Efficiency Level of Production among Sugarcane Farmers in Nyanza Region, Kenya
}

\author{
BenJack Otieno Ochieng* Scholastica Achieng Odhiambo Destaings Nyenyi Nyongesa \\ Department of Economics, Maseno University, Private Bag, Maseno, Kenya
}

\begin{abstract}
In agricultural production, labour, capital and land are critical ingredients in increasing output levels. In sugarcane and food crops production, farmers always experience competing requirements on production inputs. In Kenya, farmers are uprooting sugarcane to compensate for food deficits without due regard to the possibility that these two crops can coexist in case production inputs are in short supply. Based on production theory, this study established the cost efficiency level and the possible likelihoods sugarcane farmers, in Nyanza region, can make given the production inputs. Cross sectional data and Stratified random sampling was used. Stochastic Frontier and Multinomial Logit regressions obtained the results which showed that sugarcane farmers were cost inefficient; the significant determinant of choices that farmers make were the cost of labour and the cost of land. However, they were positive and negative respectively. This paper recommended for the betterment of wages and cost of land controls if efficiency and sugarcane output is to be increased.
\end{abstract}

Keywords: Cost efficiency, Sugarcane, Food Security, Farmers

DOI: $10.7176 / \mathrm{JESD} / 11-16-08$

Publication date:August $31^{\text {st }} 2020$

\section{Introduction}

A critical factor that determines an enterprise level of competitiveness, whether big or small is the level of efficiency which can be classified into cost, technical or allocative efficiencies. These efficiencies work together to lower per unit cost of production thereby enabling enterprises to supply their commodities at a reasonably lower cost. In this paper, cost efficiency was addressed. The definition of cost efficiency was defined in two ways i.e. the ability of a firm to produce a predetermined level of output at least cost or conversely, the ability to produce the same output with minimal cost for a given input, (Karagiannis, Katranidis, \& Tzouvelekas, 2008). Because Kenya is a developing country, expansion of efficiency is critical in order to assure economic development (Fatima \& Yasmin, 2016).

In the context of this paper, the study area comprised of sugarcane growing counties in Nyanza region, Kenya namely Kisumu, Homabay and Migori and the study focused only on sugarcane farmers who either dealt with sugarcane "only", or mixed farming i.e. sugarcane and food crops and investigated the sole factors of production namely labour (Narayan, 2004); capital (FAO, 2008) and land (Watson, Garland, Purchase, Dercas, Griffee, \& Johnson, 2008). According to Livingston, Schonberger, \& Delaney, (2011), smallholder farmers have limited access to credit to acquire farm inputs, farm and processing equipment. Once farmers have struggle to acquire these inputs, and given the myriad problems facing the sugarcane farmers, Africa Times, (2015), attempts are made by the said farmers to practice mixed farming in order to mitigate the adverse effects of sugarcane productivity, (Farmbiz Africa, 2018). Supporting this opinion was Monroy, Mulinge, \& Witwe, (2012) who contended that sugar industry in Kenya cannot meet national demand or even compete with other producers in the international market because of cost inefficiencies in the region. This observation was also supported by (Ogada, Muchai, Mwabu, \& Mathenge, (2014) who also upheld that Kenya's smallholder crop farmers were technically inefficient.

Based upon the aforementioned debates, this paper investigated, in terms of the factor inputs; the probable reasons regarding the inclination towards sugarcane "only" farming or mixed farming. It also endeavored to establish the percentage of the variances due to factor input inefficiencies as well as cost efficiency levels determination since such studies are limited within the study area.

\section{Literature review}

The importance of sugarcane in the production of sugar, alcohol, yeast and other derivatives cannot be understated (Ramashala, 2012). However, its production requires huge parcels of land (Watson, 2011). Where land is inadequate, other natural resources like forests have been cleared to facilitate their expansion, (Schneider, 2010) . While supporting this claim, De Sa, Palmer, \& Di Falco, (2013) confirmed a negative and statistically significant correlation between sugarcane expansion and deforestation. As was established by Garside, Bell, \& Magarey, (2001), long term sugarcane cultivation also affects soil properties and crop productivity negatively. This increase in production also leads to increased soil acidification, nutrient depletion and reduced soil microbial activity as well as biomass, if compared to other agricultural land uses or natural vegetation (Mardamootoo, Ng Kee, Kwong, $\&$ Preez, 2010). Gitau, (2015), pointed out that the factors promoting sugarcane farming in Western Kenya were 
land, labour, markets and good pay.

Sugarcane requires operating capital, replacement of equipment and also non -land capital (Shapouri, Salassi, $\&$ Fairbanks, 2006). The presence of these capitals has made positive contributions to sugarcane production both in the short- and long-run, (Narayan, 2004). However, even though there are farmers with sufficient land for sugarcane cultivation, these farmers may not be able to farm all their land if capital is insufficient (FAO, 2008). This is because the crop requires huge costs of production at various stages of production (Rao, 2014). Hussein \& Khattak (2011) also assessed that capital employment is closely related to sugarcane production especially on preparation of land, water management, weed control and insecticides.

Labor defines the work done by people whose value depends on workers' education, skills, motivation and productivity and whose reward is wages (Amadeo, 2017). In India, Rao, (2014) established that labour costs formed the greatest cost in sugar cane production, an observation supported also by Hussain \& Khattak, (2011) in Pakistan. In Kigali, Lankhorst \& Veldman, (2011) contended that it is strenuous to work in a sugar cane plantation since the wage rates are low compared to other forms of employment.

With regards to food security (proxied by food production), there is a potential to increase food production without increasing agricultural area in developing countries (UN, 2012). One such method of increasing food security is through agriculture intensification, which is, moving from growing one crop per year to two crops per year, (Khaleed, 2000). In Kenya, there is competition for land use among different crops but which favored sugarcane and maize at the expense of other indigenous food crops such as onions, tomatoes, cassava and sweet potatoes resulting in the persistent food insecurity (Waswa, Mcharo, \& Netondo, 2009).

With reference to food security, agricultural, ecological, micro and macro-economic policies as well as international trade are important. Zepeda, (2001) established that there is a weak relationship between food security and physical capital. Because of this, Mozumdar, (2012) proposed that human capital, research and technological development are critical in the analysis of food security.

Contrary to the popular belief, NEPAD,(2013) established that agricultural production in Africa has increased steadily but there has been very little improvement in labour since this huge production is only achieved by mobilizing a larger agricultural labour force. UN, (2013) opined that to obtain permanent economic access to food, sustainable agricultural intensification must be done only if families make optimal use of land and labour on their small land sizes and because labour is a key input in agricultural production, its loss by whatever means may lead to the reduction in the area of land under cultivation and declining yields resulting in reduced food production and food insecurity, (un.org, n.d).

\section{Methodology}

This paper used correlational research design adopted and adopted Stochastic Frontier Analysis and Multinomial Logistic Regression to establish the cost efficiency level and likelihood effects the factors of production had upon the various agricultural practices among farmers in Nyanza region, Kenya. Stratified random sampling was used and the stratas identifies from the sugarcane growing zones in Chemelil, Muhoroni, Ndhiwa and Awendo. This study sampled 190 farmers and used primary data collected through questionnaires whose reliability and validity were tested. Heteroscedasticy was tested using the Levene's test.

Using a one-step approach with a truncated normal distribution, this study incorporated the Battesse - Coeli (BC) model and the crop type to generate the cost efficiency model. The cost efficiencies are captured in Table 2 and 3 .

The econometric model for the Stochastic Frontier cost efficiency model was specified as;

$\ln T C_{i}=\alpha_{0}+\alpha_{1 i} \ln L+\alpha_{2 i} \ln K+\alpha_{3 i} \ln D+\varepsilon_{i}$

Where;

$\ln T C=$ Total cost of output

$\ln L, \ln K, \ln D=$ Cost of labour, cost of capital and cost of land, respectively

$\alpha_{1}, \alpha_{2}, \alpha_{3}=$ Random coefficients of cost of labour, cost of capital and cost of land

$\alpha_{0}=$ Constant

$i=$ Cross sectional individual farmer subscript.

$\varepsilon_{\mathrm{i}} \sim \mathrm{N}\left(0, \sigma^{2}\right)$

In order to analyze how the cost efficiency varied across the farmer type, the multinomial logistics regression econometric model was used. It was specified in equation 2 and the results captured in Table 4;

$\ln F T_{i}=\alpha_{0}+\alpha_{1 i} \ln L+\alpha_{2 i} \ln K+\alpha_{3 i} \ln D+\varepsilon_{i}$

Where;

$\ln F T=$ The farmer type (either sugarcane producer or a mixed crop producer) 
$\ln L, \ln K, \ln D=$ Cost of labour, cost of capital and cost of land, respectively

$\alpha_{1}, \alpha_{2}, \alpha_{3}=$ Random coefficients of cost of labour, cost of capital and cost of land

$\alpha_{0}=$ Constant

$i=$ Cross sectional individual farmer subscript.

$\varepsilon_{\mathrm{i}} \sim \mathrm{N}\left(0, \sigma^{2}\right)$

\subsection{Farm inputs on Crop or farmer type choice}

In this paper, there were two types of sugarcane farmers. Those who practices sugarcane "only" farming and those who practiced mixed farming, namely sugarcane and other food crops. The distribution was as follows;

Table 1: Frequencies of the Farmers

\begin{tabular}{llll}
\hline Crop type & Freq. & Percent & Cum. \% \\
\hline Sugarcane only & 33 & 16.75 & 16.75 \\
Mixed farming & 164 & 83.25 & 100.00 \\
Total & 197 & 100.00 & \\
\hline
\end{tabular}

From Table 1, sugarcane "only" farmers (type 1) were 33 representing $16.75 \%$ of the total sample while mixed crop farmers (type 2) were 164 representing $83.25 \%$ of the total farmers.

\subsection{Determination of Cost of Efficiency of Output}

The results on the variations on cost efficiency of output were presented in the Table 2.

Table 2: Variations in Total Cost of Output due to Farm Inputs

Stoc. frontier normal/tnormal model

$\begin{array}{ll}\text { Number of obs }= & 190 \\ \text { Wald chi } 2(3)= & 65.61 \\ \text { Prob }>\text { chi } 2= & 0.0000 \\ \text { Log likelihood }= & -70.5459\end{array}$

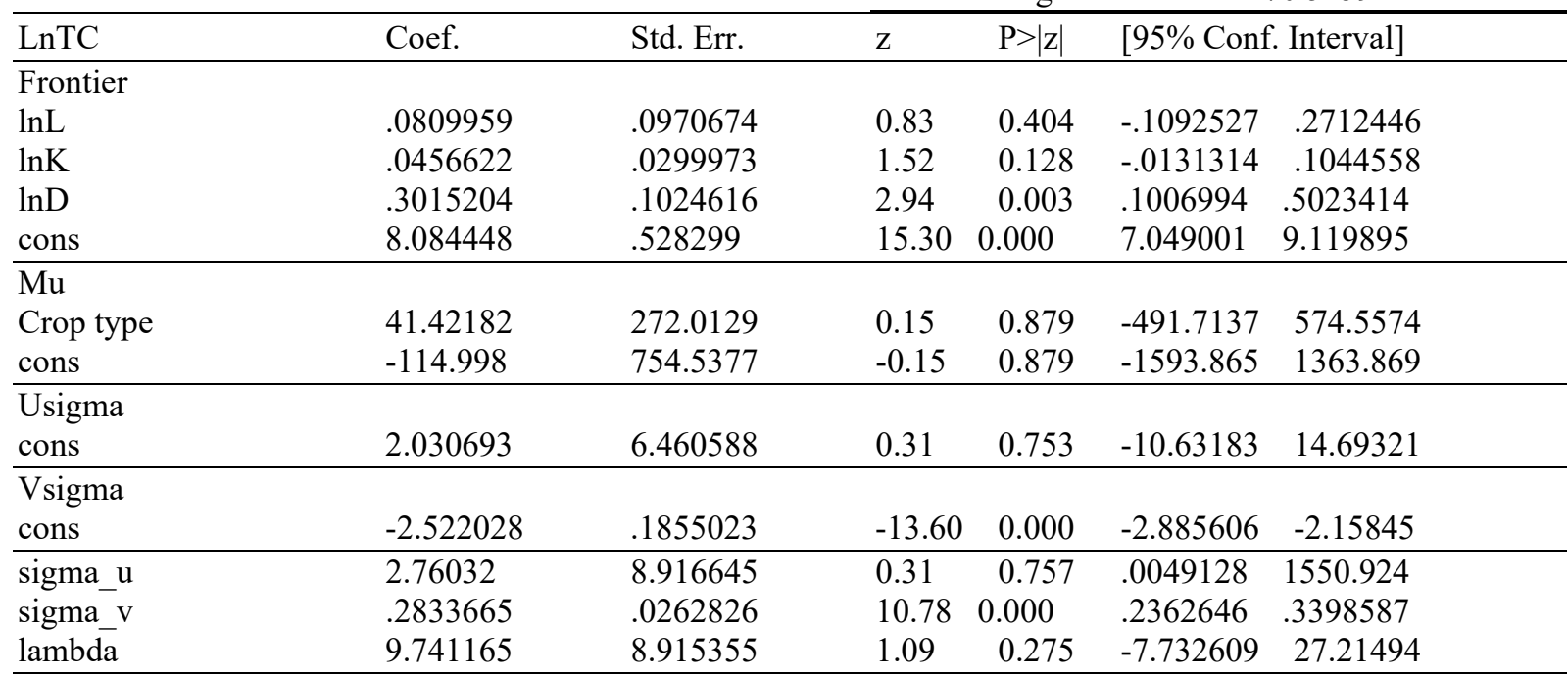

From Table 2 above, the probability of the chi-square were significant hence an indicator of a good model. From the frontier, a unit increase in the cost of land significantly increased the cost inefficiency in output production by $0.3015204\left(\alpha_{3}=0.3015204 ; p=0.003\right)$, otherwise, the cost of labour, the cost of capital and the farmer's decision were all insignificant. The standard deviation of inefficient and the random component were shown by sigma $\mathrm{u}$ and sigma $\mathrm{v}$ respectively.

Given that inefficiency component $=2.76032$ and the random component $=0.2833665$, the variance (standard deviation squared) were 7.61937 and 0.08029 respectively. Therefore the effect of the inefficiency component on the overall output was given by;

$\frac{V o I}{T V}=\frac{2.76032}{2.76032+0.2833665}=\frac{2.76032}{7.69966}=0.35849$

Where;

$\mathrm{VoI}=$ The variance of inefficiency

$\mathrm{TV}=$ The total variance. 
This calculation implied that the total variance on the cost of outputs as a result of inefficiencies was $35.849 \%$. According to (Battese \& Coelli, 1995), a stochastic frontier functions suggests the existence of technical inefficiencies for firms producing outputs. In this paper, the cost efficiency was investigated and the results of Battese -Coelli's coefficient was tabled below;

Table 3: Battesse \& Coelli coefficient

\begin{tabular}{lllllll}
\hline Variable & Obs & & Mean & Std. Dev. & Min & \multicolumn{2}{c}{ Max } \\
\hline bc & 190 &. & .8181486 & .1081179 & .3595672 & .9419181
\end{tabular}

From Table 3, the results indicated that the mean BC coefficient was 0.8181486 . This meant that the farmers cost efficiency level was at $81.81486 \%$. However, this efficiency was bounded between $18.8315 \%-93.25745 \%$. Assuming a Cobb Douglas production function, the summation of the elasticity of the production factors $0.0809959+0.0456622+0.3015204=0.4281785$ which signified a decreasing returns to scale.

\subsection{Likelihood adoption of a farming type given production inputs}

From Table 2, considering mixed farming (type 2) as the base/reference group, labour and land are elastic and significant with respect to the choice of the crop/farmer type $\left(\alpha_{1}=2.140552 ; p=0.024\right)$ and $\left(\alpha_{3}=-23.942629 ; p=0.000\right)$. This implies that a unit increase in the cost of labour is likely to increase the cost of sugarcane production by 2.140552 relative to the cost of mixed production while a unit increase in the cost of land is likely to reduce the cost of sugarcane production by 3.942629 relative to the cost of mixed production. Although cost of capital was inelastic and insignificant $\left(\alpha_{2}=0.3457222, p=0.185\right)$, a unit increase on it results into 0.3457222 increases in the cost of sugarcane production relative to the cost of mixed cropping.

Table 4: Farmer/crop type

Multinomial logistic regression

$\begin{array}{llc}\text { Number of obs } & = & 190 \\ \text { LR chi2(3) } & = & 29.45 \\ \text { Prob }>\text { chi2 } & = & 0.0000 \\ \text { Pseudo R2 } & = & 0.1710\end{array}$

$\underline{\text { Log likelihood }=-71.413741}$

\begin{tabular}{lllllll}
\hline Crop type & Coef. & Std. Err. & $\mathrm{z}$ & $\mathrm{P}>|\mathrm{z}|$ & {$[95 \%$ Conf. Interval] } \\
\hline Sugarcane & & & & & & \\
LnL & 2.140552 & .9461295 & 2.26 & 0.024 & .2861719 & 3.994931 \\
LnD & -3.942629 & .9883203 & -3.99 & 0.000 & -5.879701 & -2.005557 \\
LnK & .3457222 & .2606575 & 1.33 & 0.185 & -.1651571 & .8566014 \\
Cons & 12.9378 & 4.257262 & 3.04 & 0.002 & 4.593718 & 21.28188 \\
\hline
\end{tabular}

Mixed farming

(base outcome)

From Table 4, different signs were exhibited upon the costs of inputs. Labour and capital are positive while land is negative. The coefficients on labour and land were significant $\left(\alpha_{1}=2.140552 ; p=0.024\right) ;\left(\alpha_{2}=-3.942629 ; p=0.000\right)$. This implies that cost of labour was significantly more likely to influence a farmer to adopt sugarcane "only" production as opposed to going for mixed farming while the cost of land was significantly less likely to encourage farmers to adopt sugarcane production at the expense of mixed production. With regards to the cost of capital, the results were insignificant.

\section{Conclusion and Recommendations}

Given that this paper intended to establish the cost efficiency level of production among sugarcane farmers and to also examine the likelihood of choice of a given production line, given the factors of production namely land labour and capital, the results indicated that the farmers still suffered from cost inefficiencies in output production and the greatest factor contributing significantly to this cost inefficiency in output production was the cost of land. Therefore, this study recommended for the reduction in the cost of land within the region.

With reference to the cost of the factor/ inputs in production, this study concluded that the cost of labour was more likely to influence the adoption of sugarcane farming at the expense of mixed farming while cost of land was less likely to influence the adoption of sugarcane farming at the expense of mixed farming. Hence this paper recommends for an increase in the wage levels and a reduction in the cost of land if the region is to increase its capacity in sugarcane production.

\section{References}

De Sa, S., Palmer, C., \& Di Falco, S. (2013). Dynamics of indirect land use change: Empirical evidence from Brazil. Journal of Environment and Economic Management, 65(3), 377-393.

FAO. (2008). From Subsistence Farming To Sugar-Cane Monoculture: Impacts On Agrobiodiversity, Local 
Knowledge And Food Security. Rome: FAO.

Fatima, H., \& Yasmin, B. (2016). Efficiency and Productivity analysis of Pakistan's farm. Pakistan Journal on Agricultural Research,29(3), 312-323.

Garside, A., Bell, M., \& Magarey, R. (2001). Monoculture Yield decline- Fact not Fiction. Proceedings of the International Society of Sugar Cane Technologists, 16-20.

Hussain, A., \& Khattak, N. (2011). Economic analysis of sugarcane crop in Charsadda district, . Munich Personal RePEc Archive, 1-13.

Karagiannis, G., Katranidis, S., \& Tzouvelekas, V. (2008). Measuring technical, allocative and cost efficiencies of seabass and seabream farms in Greece. Aquaculture Economics \& Management, 4(3), 191-207.

Khaleed, S. (2000). Agricultural Land Use and Food Security in Asia: Green Revolution and Beyond. Social Science and Policy Studies.

Mardamootoo, T., Ng Kee, K., Kwong, C., \& Preez, D. (2010). History of phosphorus fertiliser usage and its impact on the agronomic phosphorus status of sugarcane soils in Mauritius. Sugar technology, 12(2), 91-97.

Mozumdar, L. (2012). Agricultural productivity and food security in the developing world. Bangladesh J. Agric. Econs. XXXV, 53-69.

Narayan, P. (2004). An empirical analysis of sugarcane production in Fiji (1970-2000). Economic Analysis \& Policy Vol 34 No.1, 53-63.

Ramashala, T. (. (2012). Sugarcane. Pretoria: Department of Agriculture, Directorate of Production.

Rao, A. (2014). Input Use and Cost of Cultivation of Sugarcane - A Study in Telangana Region of Andhra Pradesh. Journal Of Economics And Finance, 5(5), 67-74.

Schneider, L. (2010). A Sweeter Alternative for Whom? Sugarcane Ethanol Production and Rural Livelihoods in Northeast Brazil. American university.

Shapouri, H., Salassi, M., \& Fairbanks, J. (2006). The economic Feasilbility of Ethanol Production from sugarcane in the United States. Louisiana State University: OEPNU/OCE,USDA.

Waswa, F., Mcharo, M., \& Netondo, G. (2009). Enhancing household food and income security through crop diversification in the Nzoia and Mumias sugarbelts in Kenya. Journal of Applied Biosciences, 1406-1415.

Watson, H. (2011). Potential to expand Sustainable Bioenergy from sugarcane in South Africa. Energy policy 39(10), 5746-5750.

Watson, H., Garland, G., Purchase, B., Dercas, N., Griffee, P., \& Johnson, F. (2008). Bioenergy for sustainable Development and global Competitiveness; The case of sugarcane in Southern Africa. Durban, SA: Agriculture Cane Resources Network for Southern Africa.

Zepeda, L. (2001). Agricultural Investment, Production Capacity and Productivity. In J. Vercueil, Agricultural Investment and productivity in Developing Countries (p. 148). FAO. 